\title{
A construção discursiva de Xuxa como promotora da inclusão social
}

\section{The Discursive Construction of Xuxa as a Promoter of Social Inclusion}

\author{
Dánie Marcelo de Jesus* \\ Universidade Federal de Mato Grosso \\ Cuiabá - Mato Grosso/Brasil \\ Fernando Zolin-Vesz** \\ Instituto Federal de Educação, Ciência e Tecnologia de Mato Grosso \\ Cuiabá - Mato Grosso/Brasil
}

\begin{abstract}
RESUMO: Neste artigo, analisamos o texto "Xuxa promove a magia da inclusão", publicado na edição n. 993 da revista Caras, a fim de compreender, por meio da associação entre as escolhas verbais e não verbais, como o referido texto constrói/ perpetua, discursivamente, Xuxa como promotora da inclusão social, em especial de crianças com síndrome de Down. Os resultados da análise apontam a manutenção, a um só tempo, da representação de Xuxa como serva dos baixinhos, com base na comodificação de sua imagem, que constitui a origem da representação de Xuxa promotora da inclusão social, e de um discurso sedimentado na concepção de uma inclusão essencialista, forjada em uma visão baseada no exótico, que parece homogeneizar a inclusão social dos portadores da síndrome de Down.
\end{abstract}

PALAVRAS-CHAVE: discurso; promoção da inclusão social.

ABSTRACT: This paper focuses on the article "Xuxa promove a magia da inclusão" (in English, "Xuxa promotes the magic of inclusion"), published in the 993 edition of Caras magazine. The aim is to reveal, by associating verbal and nonverbal choices, how the text discursively constructs and/or perpetuates Xuxa as a promoter of social inclusion, particularly regarding children with Down syndrome. Analysis results suggest the maintenance of both the representation of Xuxa as a servant of kids based on her commodified image - which gives rise to her representation as a promoter of social inclusion - and of a discourse set on an essentialist concept of inclusion, which is grounded on an exotic-based perspective that seems to homogenize the social inclusion of children with Down syndrome. KEYWORDS: discourse; social inclusion promotion.

\footnotetext{
*daniepuc@gmail.com

**fernando.vesz@blv.ifmt.edu.br
} 


\title{
Introdução
}

\author{
Eu sou diferente de você \\ Você é diferente de mim \\ Eu sou diferente de você e mesmo assim \\ Você vai gostar de mim $^{1}$
}

No mundo do entretenimento brasileiro, poucas figuras se tornaram tão bem sucedidas quanto Xuxa, a "Rainha dos Baixinhos". Desde a década de 1980, a apresentadora vem se destacando como um dos maiores ícones da televisão, da indústria fonográfica e do cinema (ZOLIN-VESZ; JESUS, 2012; ZOLINVESZ, 2013). Em sua trajetória de sucesso, Xuxa edificou uma efígie de protetora/defensora da infância brasileira de tal forma, que se transformou em um fenômeno da mídia contemporânea, com forte impacto no imaginário da sociedade brasileira. Suas participações em diversas campanhas sociais em prol dos baixinhos e a fundação assistencial que mantém podem servir de exemplo. Apesar de ter se tornado um mito de massa, poucos trabalhos acadêmicos na seara do discurso (SIMPSON, 1993; VALDIVIA; CURRY, 1998, 2000; ZOLINVESZ; JESUS, 2012; ZOLIN-VESZ, 2013) se preocuparam em estudar as construçōes discursivas de sua imagem. Compreender esse fenômeno é também entender como a mídia representa as pessoas e as coisas.

Neste artigo, portanto, buscamos analisar um aspecto profundamente relacionado com a criação do mito Xuxa - sua representação como promotora da inclusão social - a partir do texto intitulado "Xuxa promove a magia da inclusão", publicado na edição n. 993 da revista Caras, em 16-11-2012. Este texto, além de trazer uma entrevista com a apresentadora, apresenta as fotos que Xuxa estrelou, em conjunto com crianças portadoras de síndrome de Down, que iriam compor o calendário Happy Down 2013. O objetivo do calendário é incentivar a inclusão social de crianças e jovens com síndrome de Down, por meio da desmistificação do tema, somada ao estímulo ao respeito e à diversidade humana, como afirma, no texto, uma das fundadoras do Grupo Happy Down, que idealizou o calendário. O intuito da publicação da entrevista e das fotos na revista parece ser a divulgação do calendário, uma vez que o texto encarta o valor e os locais de compra do produto.

\footnotetext{
${ }^{1}$ Excerto da canção "Você vai gostar de mim", que compõe o álbum Xuxa Só Para Baixinhos 10 - Baixinhos, Bichinhos e +, lançado em 2010 pela gravadora Sony Music.
} 
Dessa forma, investigamos como o referido texto constrói/perpetua, discursivamente, Xuxa como promotora da inclusão social de crianças e jovens com síndrome de Down. Discurso é aqui entendido como práticas sociais que, simbolicamente, dispõem o mundo em significações, desenhando as identificaçōes dos indivíduos e suas relaçōes sociais, bem como suas representações e seus conhecimentos (FAIRCLOUGH, 2001). Esquadrinhando o referido texto, podemos compreender também como o sujeito portador de necessidade especial é caracterizado nas fotos que compõem o calendário. A análise, portanto, considera que todo discurso imagético ou verbal é ideológico ${ }^{2}$ e colabora para a construção de determinada realidade, especialmente na mídia, em que o não verbal integra a constituição do verbal (FAIRCLOUGH, 2001; KRESS; LEEUWEN, 2007). Sendo assim, as escolhas verbais e não verbais podem revelar um efeito ideológico de sustentação e manutenção de determinados discursos capazes de conduzir para um sentido único, essencialista. Daí o interesse deste trabalho em focalizar, para além das circunstâncias do texto escrito, as imagens que fazem parte da situação discursiva.

Antes da análise, porém, propomos uma discussão acerca da "institucionalização de Xuxa" como "a serva dos baixinhos", conforme proposta por Simpson (1993) e Valdivia e Curry (1998; 2000). Tal concepção foi sendo discursivamente construída por meio de seus programas infantis nas décadas de 1980 e 1990, constituindo os fundamentos para a compreensão de sua representação também como promotora da inclusão social.

\section{A institucionalização de Xuxa como a serva dos baixinhos}

Simpson (1993), o pioneiro e principal trabalho a buscar analisar e interpretar o fenômeno Xuxa, examina, de igual modo, como o incentivo de Xuxa ao consumismo representa a expressão fundamental da criação mítica da apresentadora como devota de servir os interesses das crianças. Resumidamente, o estudo de Simpson gira em torno de três eixos - gênero (gender), raça (race) e modernidade (modernity). Desfiam aspectos da cultura brasileira que estão refletidos nas características definidoras do estrelato de Xuxa: sua representação

\footnotetext{
${ }^{2}$ Ideologias são significações/construções da realidade - o mundo físico, as relações sociais e as identidades sociais -, construídas em várias dimensões das formas/ sentidos das práticas discursivas que contribuem para a produção, para a reprodução ou para a transformação das relações de dominação (FAIRCLOUGH, 2001).
} 
de feminilidade [gênero], sua exclusiva beleza branca [raça] e a promoção de uma ideia de cultura e modernidade baseada no consumismo. ${ }^{3}$

Em decorrência de sua análise sobre a "fórmula" do programa Xou da Xuxa, exibido pela Rede Globo de 1986 a 1992, a autora observa que "Xuxa se retrata como serva do público, respondendo, mas não criando demanda" (SIMPSON, 1993, p. 99) - os produtos comercializados com a marca Xuxa são pensados em resposta aos desejos e anseios dos baixinhos. Nessa marcha, constata ainda a autora, essa benevolência é a faceta por trás do considerável império que Xuxa desenvolveu.

Já Valdivia e Curry (1998, 2000), por meio de suas análises tanto da versão brasileira quanto das versōes em espanhol e em inglês dos programas de Xuxa, denotaram que estes constroem as crianças e a apresentadora como consumidores e produto consumido, respectivamente. Sendo assim, as crianças também se tornam comodificadas. Para as autoras, a insistência de Xuxa em (re)afirmar que seus programas ajudam a empoderar as crianças, consideradas um grupo social altamente marginalizado, contribui para a comodificação das crianças, pois, na condição de "Rainha dos Baixinhos", "[...] a maior parte do poder que seus programas conferem às crianças se traduz como a capacidade de servir à sua rainha por meio do consumo da própria Xuxa e dos produtos licenciados" (VALDIVIA; CURRY, 2000, p. 135). Portanto, lembram as autoras, esse empoderamento apenas ocorre para aquelas crianças que podem comprar os produtos anunciados e participar dos programas.

Como se vê, alicerçada na pesquisa acadêmica da década de 1990, a criação mítica de Xuxa como a serva das crianças teve sua origem calcada na comodificação da imagem da apresentadora, na forma tanto de seus programas como dos produtos de sua marca. A necessidade de Xuxa em (re)afirmar os direitos, a importância e o poder dos baixinhos se vincula, portanto, à própria criação mítica dela. Daí a recorrência também desses temas em suas canções, corroborada pelo excerto na epígrafe deste artigo. Como serva, Xuxa se torna a porta-voz dos direitos dos baixinhos a terem seus anseios reconhecidos e respeitados, preferencialmente por meio do consumo de seus DVDs infantis, além dos demais produtos licenciados com sua marca.

\footnotetext{
${ }^{3}$ Para uma análise do estudo de Simpson, veja Zolin-Vesz (2013).

${ }^{4}$ Todas as traduções são de nossa autoria.
} 


\section{Xuxa, a vendedora da inclusão social}

Como mencionamos em passo anterior, é a condição de serva dos baixinhos que configura a origem da representação de Xuxa como a promotora da inclusão social. Dessa forma, durante a entrevista, a apresentadora parece buscar reiterar essa condição.

- Você é engajada em muitas causas sociais. Tem a dimensão da sua força como pessoa pública?

- O que sei é que gosto bastante de participar de projetos como este [o calendário]. É algo que peço às pessoas. Mas acho que muitas não acreditam ou têm vergonha de me chamar. Mas volto a dizer: 'me usem, gente'. Sei que tenho um espaço, como este que a CARAS está me dando, por exemplo, onde posso falar de assuntos importantes, das necessidades deles. Trabalho para crianças, não importa se estão numa cadeira de rodas ou não, se são autistas, surdos... Minha preocupação é com o bem-estar e a proteção.

Neste excerto da entrevista, Xuxa parece assumir sua devoção em servir às crianças. Além de porta-voz de suas necessidades, a apresentadora explicita que seu trabalho é em favor delas, independentemente de qualquer limitação física ou mental. Como porta-voz e serva, portanto, sua luta em defesa da infância é que os direitos das crianças sejam respeitados, como o direito ao bemestar e à proteção.

Assim, os produtos licenciados com a marca Xuxa, como seus DVDs, por exemplo, são pensados para atender e servir a um direito básico das crianças - o bem-estar. Mesmo tendo sido, seu DVD mais recente, indicado a um prêmio importante - o Xuxa Só Para Baixinhos 11 foi apontado ao Grammy Latino 2012 na categoria de melhor álbum infantil ${ }^{5}$-, Xuxa, na condição de serva dos baixinhos, reitera a importância de que seu trabalho atinja o objetivo de proporcionar bem-estar às crianças. $\mathrm{O}$ fato de as crianças "curtirem" os produtos que são pensados e destinados somente para elas - Xuxa Só Para Baixinhos - é sinalizado pela apresentadora como um prêmio, por si só.

- O DVD anterior, o 11, recebeu agora a indicação ao Grammy Latino como Melhor Álbum Infantil...

\footnotetext{
${ }^{5}$ Além do Xuxa Só Para Baixinhos 11, os álbuns Xuxa Só Para Baixinhos 2, Xuxa Só Para Baixinhos 3 e Xuxa Só Para Baixinhos 4 também foram indicados ao Grammy Latino na categoria de melhor álbum infantil nos anos de 2002, 2003 e 2004, respectivamente. Os álbuns Xuxa Só Para Baixinhos 2 e Xuxa Só Para Baixinhos 3 foram vencedores.
} 
Xuxa - Para mim, o que mais importa, de verdade, é ver as crianças cantando, dançando e se divertindo. Muita gente até se chateia quando digo isso. Eu agradeço, acho um reconhecimento bacana, mas meu maior prêmio é continuar a vê-las curtindo o meu trabalho. Isso é um Grammy para mim.

Por assim ser, a inclusão social que Xuxa promove se dá justamente com base na devoção da apresentadora às crianças por meio de seus produtos.

Andrea Barbi-Xuxa sempre deu muita força para a causa em todos os seus trabalhos e, principalmente, no Só Para Baixinhos. Ela é uma profissional incrível, por isso a gente sempre quis tê-la no projeto. Usa a linguagem dos surdos, conta com criança com síndrome de Down ou cadeirantes em seus vídeos. Então, o trabalho dela é muito importante. Não só na forma como trata de igual para igual, mas também em sua preocupação. Conheço casos de baixinhos que aprenderam as cores e a contar a partir do XSPB. Com isso, ela tem participação importantíssima na parte de inclusão social.

O depoimento de Andrea Barbi, uma das fundadoras do Grupo Happy Down, a quem coube idealizar o calendário, caminha no sentido de sintetizar a contribuição de Xuxa para a promoção da inclusão social. Esta se dá por meio do consumo dos produtos da apresentadora. Dessa forma, a inserção de crianças portadoras da síndrome de Down ou o uso da linguagem de sinais se inclina para constituir um artifício empregado por Xuxa na comodificação da inclusão social. Este parece ser o ponto de intersecção entre as primeiras pesquisas de Simpson (1993) e Valdivia e Curry (1998; 2000) sobre a institucionalização de Xuxa, ideada a serva dos baixinhos, e sua representação também como promotora da inclusão social - a comodificação de sua imagem por meio de diversos produtos, a exemplo dos DVDs, para atender a direitos básicos das crianças, como o da inclusão social.

\section{Afinal, que inclusão é essa?}

Como já abordamos, todo discurso imagético ou verbal colabora para a construção de determinada realidade. No caso de Xuxa, a revista se esforça por procurar descrevê-la como alguém que, inexoravelmente, se preocupa com crianças portadoras da síndrome de Down. Por essa razão, um dos recursos no título do texto - "Xuxa promove a magia da inclusão" - é revesti-la como alguém com o poder de alterar, com um toque de fantasia, a realidade dessas crianças. Assim, pelo menos momentaneamente, elas deixaram de ser excluídas socialmente para assumir o estatuto de especiais, em um mundo onírico povoado por princesas, reis e rainhas. 
A imagem de abertura do texto ${ }^{6}$ nos desfila Xuxa, no centro, como a princesa Bela e as crianças, ao seu lado, representando a Fera, o candelabro e o relógio. É perceptível que a apresentadora é exposta como protagonista da cena, ao passo que as crianças "atuam" como coadjuvantes. Essa imagem parece procurar criar uma aparente inclusão dessas crianças, no mundo mágico de Xuxa. Ao estabelecer essa identificação, a apresentadora se inclina a reforçar seu espaço simbólico de defensora desse público infantil. Contudo, as crianças, ao serem retratadas como personagens secundários, se tornam simplesmente apêndices.

No serem tematizadas, as crianças com síndrome de Down são apenas evidenciadas, e não apresentadas como sujeitos de direito. Tal representação parece corroborar a ideia da não alteração dos lugares sociais estabelecidos para o portador da síndrome. Essa percepção é reforçada pelo depoimento de um dos integrantes da foto: "Eu sou a Fera e Xuxa, minha Bela". Ao se configurar como animal, a criança adiciona a seu discurso a representação do que seja um portador de necessidade especial. Ao longo da história, a imagem de "fera" foi sempre disposta por meio de discursos hegemônicos de normatização e controle sobre os corpos daqueles que tinham algum tipo de comportamento não "natural" (SKLIAR, 2005). Em tempo passado, por exemplo, essas crianças eram representadas como seres bizarros, presas malignas de entidades extracorpóreas (CECCIM, 2006).

A personagem Branca de Neve, incorporada por Xuxa na segunda imagem, ${ }^{7}$ em conjunto com crianças portadoras da síndrome de Down, representadas como os sete anōes, tende, igualmente, a reforçar a apresentadora como a figura central.

De modo análogo ao que se deu na imagem anterior, as crianças com síndrome de Down apenas representam objetos decorativos, dado que relegadas à importância marcadamente secundária, para compor a história de inclusão. Semelhantemente à fera, os anōes sempre foram vistos como seres estranhos, ou folclóricos, em nossa representação social. Ao agir dessa forma, as crianças acabam sendo fixadas como indivíduos apenas diferentes - ao invés de se tornarem personagens ativos no espetáculo. Em suma, apenas adornam, assim como os anões de um jardim. Além disso, parece também revelar uma

\footnotetext{
${ }^{6}$ Imagem disponível em: http://caras.uol.com.br/revista/993/secao/destaques/xuxapromove-magia-da-inclusao\#image 0 .

${ }^{7}$ Imagem disponível em: http://caras.uol.com.br/revista/993/secao/destaques/xuxapromove-magia-da-inclusao\#image 12.
} 
hegemonia cultural cristalizada que procura homogeneizar os discursos sobre inclusão. Assim, alguém que enxerga a imagem como simples recurso ilustrativo e inclusivo pode ignorar a relação de poder e efeito ideológico de tal prática - a percepção social sobre o diferente como exótico. É o discurso neoliberal que marca a diversidade, sem, no entanto, revesti-la de poder.

Já na terceira imagem, ${ }^{8}$ esta nos reporta à história de Pinóquio, um boneco de madeira, esculpido por Geppetto, que sonhava em ser um menino de verdade. Xuxa, centralmente posicionada, é apresentada como a entalhadora do boneco, enquanto as crianças são retratadas como Pinóquio e o Grilo Falante.

Novamente, os papeis atribuídos a cada um dos indivíduos na imagem não nos transpiram algo aleatório. $\mathrm{Na}$ esteira de Pinóquio, a criança com síndrome de Down sempre foi descrita como um ser incompleto, com pouco desenvolvimento de aprendizagem, tida por tábula rasa que deveria ser esculpida (CECCIM, 2006). Uma tentativa de homogeneizar seu comportamento, identificando-o ao das crianças consideradas normais.

Nesse molde, a inclusão esbarra na dicotomia "normal" versus "anormal", a despeito da tentativa de apagamento dessa polarização no discurso do projeto do calendário. Apenas Xuxa, com sua magia, tem o poder fictício de transformar madeira rústica em um menino de verdade. Assim, parece-nos que se mantém um discurso essencialista, cujos indivíduos não são entendidos em sua complexidade histórica. Portanto, ao invés de um discurso que assume a diferença como parte constitutiva da humanidade, temos a perpetuação da negação dessa diferença, à medida que a transformação em criança de verdade apenas se dá no mundo dos sonhos de Xuxa.

Por fim, na quarta imagem, ${ }^{9}$ Xuxa assume novamente o papel central. Dessa vez, como o personagem "o vagabundo", do filme $O$ Garoto de Charles Chaplin.

A imagem intenta reproduzir a clássica cena de Chaplin com o menino pobre. Contudo, diferentemente do filme, em que os personagens parecem contemplar os telespectadores, neste caso a criança observa a apresentadora como se estivesse extasiada com sua presença, cabendo a Xuxa configurar-se com semblante pueril. Essa sutil diferença entre a imagem e a cena original nos parece fortalecer a concepção de Xuxa como protetora dos baixinhos com

\footnotetext{
${ }^{8}$ Imagem disponível em: http://caras.uol.com.br/revista/993/secao/destaques/xuxapromove-magia-da-inclusao\#image11.

${ }^{9}$ Imagem disponível em: http://caras.uol.com.br/revista/993/secao/destaques/xuxapromove-magia-da-inclusao\#image2.
} 
síndrome de Down. Assim como o personagem de Charles Chaplin no filme, na imagem Xuxa luta contra as intempéries da vida para salvar uma criança abandonada, que, neste caso, é portadora da síndrome. É essa simbologia que confere à apresentadora condição para se tornar a promotora da inclusão social, pois, ao mergulhar no lindo mundo de Xuxa, aproxima-se da representação desejada de uma sociedade sem barreiras sociais, isenta de impurezas. Entretanto, esse sonho se estilhaça à medida que a almejada inclusão se dilui perante sua presença como a estrela da imagem.

Certamente, aqueles que defendem esse tipo de inclusão social se esquecem das decorrências ideológicas e políticas dessa postura essencialista. A falta de uma reflexão mais detalhada sobre a homogeneização dos discursos sobre inclusão, e seus efeitos sociais, históricos e educacionais, podem trazer efeitos contrários ao desejado.

\section{Considerações (não) finais}

Neste artigo, analisamos o texto "Xuxa promove a magia da inclusão", publicado na revista Caras. Por meio da associação entre as escolhas verbais e não verbais, objetivamos compreender, a um só tempo, a representação da apresentadora Xuxa promotora da inclusão social e da inclusão de crianças com síndrome de Down. Esse o projeto que originou o texto em análise.

Percebemos que o discurso está sedimentado na concepção de uma inclusão essencialista, forjada em uma visão baseada no exótico. A opção em reproduzir cenas de clássicos do cinema, principalmente os infantis, procura aproximar a criança portadora da síndrome de Down com o mundo mágico de Xuxa. Contudo, da maneira como as fotos estão dispostas, apenas a apresentadora tem o destaque merecido. As crianças, por sua vez, são expostas como acessórios que auxiliam na manutenção do mito midiático. Xuxa, portanto, sempre é constituída como uma celebridade preocupada com a infância. Se bem assim, tal preocupação está diretamente encadeada com a autopromoção, identificando-a como estrela do universo infantil do entretenimento. A única forma de uma criança ingressar nesse espaço encantado, em que Xuxa habita, é indubitavelmente por meio de seus produtos. Projetando-se como consumidora, a criança com síndrome de Down pode afirmar sua diferença. É nesse lugar que há harmonia na diversidade e igualdade de oportunidades, ou, como Xuxa canta em um de seus DVDs infantis, eu sou diferente de vocêlvocêé diferente de mim/eu sou diferente de você e mesmo assim/ você vai gostar de mim. 
$\mathrm{Na}$ esteira de Fairclough (2001), porém, acreditamos que é possível compreender e talvez alterar certas concepções que nutrem os discursos hegemônicos, em particular aqueles que parecem homogeneizar a inclusão social dos portadores da síndrome de Down. Assim, podemos refletir e nos (re)constituir para que um dia possamos encontrar caminhos para uma sociedade de fato inclusiva.

\section{Referências}

CECCIM, R. B. Exclusão da alteridade: de uma nota de imprensa a uma nota sobre a deficiência mental. In: SKLIAR, C. (Org.). Educação e exclusão: abordagens socioantropológicas em educação especial. 5. ed. Porto Alegre: Mediação, 2006.

FAIRCLOUGH, N. Discurso e mudança social. Tradução de Izabel Magalhães. Brasília: Editora da UnB, 2001.

KRESS, G.; VAN LEEUWEN, T. Reading images: the grammar of visual design. 2. ed. Londres/Nova York: Routledge, 2007.

SIMPSON, A. Xuxa. The mega-marketing of gender, race, and modernity. Philadelphia: Temple University Press, 1993.

SKLIAR, C. Os estudos surdos em Educação: problematizando a normalidade. In: SKLIAR, C. (Org.) A surdez: um olhar sobre as diferenças. 3. ed. Porto Alegre: Mediação, 2005.

VALDIVIA, A. N.; CURRY, R. Xuxa at the borders of global TV: the institutionalization and marginalization of Brazil's blonde ambition. Camera Obscura, n. 38, p. 31-59, 1998.

VALDIVIA, A. N.; CURRY, R. Xuxa!: can Latin Americans be blonde or can the United States tolerate a Latin American? In: VALDIVIA, A. N. A Latina in the land of Hollywood and other essays on media culture. Tucson: The University of Arizona Press, 2000, p. 125-147.

ZOLIN-VESZ, F.; JESUS, D. M. A constituição discursiva da predestinação de Xuxa. Signótica, v. 24, n. 2, p. 323-338, 2012.

ZOLIN-VESZ, F. O discurso científico/colonialista norte-americano sobre Xuxa. Revista Brasileira de Linguistica Aplicada, v. 13, n. 1, p. 245-257, 2013. 


\section{ANEXO}

\section{XUXA PROMOVE A MAGIA DA INCLUSÃO}

\section{Crianças com síndrome de Down são astros de cinema em um calendário}

Momentos antes de posar ao lado de Xuxa Meneghel (49) em uma cena do clássico infantil A Bela e A Fera, o menino Phelipe de Alencar (8), que tem síndrome de Down, mostrava-se extremamente concentrado. A ponto de pouco se mexer na poltrona. " $E u$ sou a Fera e Xuxa, minha Bela", avisou. Enquanto isso, Wellington Souza (5), o Relógio, dava risada e Ana Luisa Scapin (3), o Candelabro, começou a jogar bola com a apresentadora, que abriu as portas da sua casa, no Rio, para fotografar o calendário Happy Down 2013. "Eu amei tudo e me diverti bastante na companhia deles", ressaltou. Neste clima de alegria, descontração e amor, Xuxa recebeu 40 crianças e jovens com a ocorrência genética, e outras sem a síndrome, como incentivo à inclusão, para produzir cenas retratadas pelo fotógrafo Leonardo Luz (54). E embarcou na magia de clássicos do cinema como Alice no País das Maravilhas, A Pequena Sereia, O Mágico de Oz, Branca de Neve, Harry Potter, Peter Pan, Pinóquio, A Bela e a Fera e Piratas do Caribe além do personagem $O$ Garoto, de Charles Chaplin. "Eles me deixaram dar vários pitacos. Gostei muito da maquiagem do pirata e me apaixonei pela Ariel. O que mais estava a fim de fazer era mesmo a Branca de Neve, porque havia sete bebês ali como os anões. O engraçado é que uns batiam nos outros, se empurravam, foi uma farra. E teve um menininho que dormiu no meu colo. Disse que não tinha problema, era o Soneca", divertiu-se ela, que fotografou parte do projeto ainda com o cabelo na cor castanhoescuro, por conta de uma campanha publicitária. Mas, na capa, ela já aparecerá novamente loira o lado da atriz Paula Werneck (25) e de Gabriela Pallotino (7), Iago La Yunta (2) e Yvy Faria (7), caçula do ex-jogador e atual deputado federal Romário (46), da união com Isabella Bittencourt (31), de quem está separado.

Quem também chamou a atenção horas antes de sua performance foi Claudio Aleoni (27). Ele não queria fazer feio ao encarnar o par de sua apresentadora preferida ao reproduzir memorável cena do clássico Titanic, na proa do navio, eternizada no cinema por Leonardo Di Caprio (37) e Kate Winslet (36). "Claudio estava emocionado. Ele se preparou muito, interpretou mesmo”, disse, eufórica, Xuxa. Com a tarefa cumprida, o jovem falou entusiasmado sobre a experiência. "Claudio Jack e Xuxa Rose sentiram o vento no rosto... Fiquei muito feliz de estar com ela, é uma grande amiga", contou ele, fazendo uma brincadeira com os nomes dos personagens.

$\mathrm{O}$ anuário, que chega à sétima edição, a quarta realizada com o apoio de famosos e a primeira protagonizada por um único artista, foi idealizado pelo Grupo Happy 
Down, que tem Andrea Barbi (42) e Audrey Bosio (35) como fundadoras, mães de Nathalia (9) e Isabella (9), ambas com a síndrome. O objetivo é levar à reflexão para mostrar que as crianças e jovens são indivíduos como quaisquer outros, com potencialidades e direitos. "Buscamos desmistificar o tema, estimulando a inclusão social e o conceito de respeito à diversidade humana", explicou Andrea, que ressaltou ainda a receptividade de Xuxa. "Foi uma surpresa extremamente agradável. Sempre gostei dela na televisão, mas, de repente, a vejo em sua casa, megassimples, querida, andando descalça, se divertindo sentada no chão com os pequenos. A gente percebia que era algo de coração, de emoção mesmo", atestou. Toda a renda com a venda do calendário será revertida para o Grupo Síndrome de Down da Associação das Voluntárias do Hospital Infantil Darcy Vargas, em São Paulo, e beneficiará mais de 170 famílias carentes. E poderá ser encontrado, a partir de $\mathrm{R} \$ 19,90$, nas unidades da Livraria Cultura, no site www.livrariacultura.com.br e também na loja da Fnac na Barra da Tijuca, no Rio.

\section{- Como recebeu o convite para estrelar o calendário?}

Xuxa - Nas outras edições, cada artista tinha feito uma única foto, então, logo perguntei: 'vou fazer uma só?' E me disseram que a ideia era que eu estivesse em todas. Aceitei na hora. É um trabalho muito lindo. E quem está à frente, chamando as pessoas, divulgando, são duas mães que têm filhos com síndrome de Down. Todos deveriam se tocar e ajudar na luta pela inclusão. Eles são pessoas que necessitam de uma atenção diferente, mas têm seus direitos, precisam trabalhar, e de escolas preparadas para recebê-los. Há pouco tempo puderam até votar.

Andrea Barbi - Xuxa sempre deu muita força para a causa em todos os seus trabalhos e, principalmente, no Só Para Baixinhos. Ela é uma profissional incrível, por isso a gente sempre quis tê-la no projeto. Usa a linguagem dos surdos, conta com criança com síndrome de Down ou cadeirantes em seus vídeos. Então, o trabalho dela é muito importante. Não só na forma como trata de igual para igual, mas também em sua preocupação. Conheço casos de baixinhos que aprenderam as cores e a contar a partir do XSPB. Com isso, ela tem participação importantíssima na parte de inclusão social.

- O que mais chama a atenção nas crianças e jovens com a síndrome? Xuxa - Eles são apaixonantes, beijam demais, são muito carinhosos. Alguns também são bastante carentes. Mesmo nas fases adolescente e adulta, não perdem a pureza, a essência da infância. E todos sabem do meu amor por crianças, as considero anjos. Elas olham para mim diferente, então, me sinto uma pessoa especial. Vejo estes cotoquinhos lindos, fico boba, eles são a minha tomada de energia. 
- Você é engajada em muitas causas sociais. Tem a dimensão da sua força como pessoa pública?

- O que sei é que gosto bastante de participar de projetos como este. É algo que peço às pessoas. Mas acho que muitas não acreditam ou têm vergonha de me chamar. Mas volto a dizer: 'me usem, gente'. Sei que tenho um espaço, como este que a CARAS está me dando, por exemplo, onde posso falar de assuntos importantes, das necessidades deles. Trabalho para crianças, não importa se estão numa cadeira de rodas ou não, se são autistas, surdos... Minha preocupação é com o bem-estar e a proteção.

- É verdade que, devido ao cabelo escuro, alguns pequenos estranharam você? Xuxa - A Naná (filha de Andrea) não me reconheceu. Fiquei arrasada! Ela não me olhava, nem me dava bola. Tanto que estava curtindo ser morena, podia ficar mais um tempo, mas a minha vontade de voltar a ser loira surgiu porque tinha que fazer a foto da capa e da divulgação do calendário. E como a Naná ia participar, pensei: 'pelo amor de Deus, preciso estar loira'. (risos)

Andrea Barbi - Teve um momento engraçado também quando ela estava vestida de Gepeto. O menino que fazia o Pinóquio, o Leonardo, estava agitado, brincando ao seu lado e nem ligava para a Xuxa. Daí alguém põe em um Ipad um vídeo dela. E, imediatamente, ele começou a gritar: 'Xuxa, é a Xuxa'. E ela ali do lado, dizia: 'tá bom, aproveita esta Xuxa aî'. (risos)

- Xuxa, você também está envolvida no XSPB 12, que deve ser lançado em 2013. Qual o diferencial para as outras edições?

- Foi um dos motivos para que eu voltasse a ser loira logo, já que é um trabalho direcionado aos pequenos. O tema será dança. Vamos ensinar samba, lambada, funk, chula. Nossa ideia é mostrar que existem várias maneiras das pessoas se soltarem. Tem uma canção que fala: 'mil maneiras de andar, mil maneiras de dançar...' Então, não importa se uma acompanha mais rápido, outro devagar, o bacana é experimentar. Teremos este ano as participaçôes especiais do Alexandre Pires, Buchecha, Michel Theló e Daniel.

\section{- O DVD anterior, o 11, recebeu agora a indicação ao Grammy Latino como Melhor Álbum Infantil...}

Xuxa - Para mim, o que mais importa, de verdade, é ver as crianças cantando, dançando e se divertindo. Muita gente até se chateia quando digo isso. Eu agradeço, acho um reconhecimento bacana, mas meu maior prêmio é continuar a vê-las curtindo o meu trabalho. Isso é um Grammy para mim.

Recebido em 19/05/2013. Aprovado em 07/08/2013. 